\title{
Adoption of E-Government among Bahraini Citizens
}

\author{
Mohamed Meftah ${ }^{1}$, Behrooz Gharleghi ${ }^{1,2} \&$ Behrang Samadi ${ }^{1}$ \\ ${ }^{1}$ Faculty of Business and Management, Asia Pacific University of Technology and Innovation, Bukit Jalil, Kuala \\ Lumpur, Malaysia \\ ${ }^{2}$ Centre for the Socio-Economics of Ageing (CSEA), Asia Pacific University of Technology and Innovation, \\ Kuala Lumpur, Malaysia \\ Correspondence: Behrooz Gharleghi, Faculty of Business and Management, Asia Pacific University of \\ Technology and Innovation, TPM, 57000, Bukit Jail, Kuala Lumpur, Malaysia. Tel: 60-19-615-3515. E-mail: \\ behrooz@apu.edu.my
}

\author{
Received: August 28, 2014 Accepted: November 14, 2014 Online Published: January 14, 2015 \\ doi:10.5539/ass.v11n4p141 \\ URL: http://dx.doi.org/10.5539/ass.v11n4p141
}

\begin{abstract}
Many governments worldwide have been investing heavily in e-Government project as a strategy to provide the best governmental services to citizens. However, many governments and academic researchers recognized the problem of low-level of citizens' adoption toward e-Government services. Bahrain e-Government Authority is one of the governments that suffer from the lack of citizens' adoption of e-Government services, what caused serious problems to the authority. Therefore, this study is dedicated to address the factors that affect citizen's intention to adopt e-Government services from cultural, awareness and trust perspectives. Regression analysis is conducted to determine the relationship between culture, awareness and trust with adoption of e-Government. The results of the regression test showed strong evidence of a significant relationship between culture, awareness and trust and adoption of e-Government. However, the test indicated that trust had the highest level of relationship toward e-Government adoption. These results reveal that trust construct should be more considered by the e-Government authorities in Bahrain because it has a considerable impact on citizens' intention to use e-Government services. This will enable the authority to take actions to enhance citizens' trust, what will increase the rate of e-Government adopters.
\end{abstract}

Keywords: awareness, culture, e-government adoption, trust

\section{Introduction}

Due to the important position the government has, it has implemented technology and information system in order to serve the citizens and businesses effectively and efficiently, when the concept of e-government was born. "E-Government" refers to the use by government agencies of information technologies (such as Wide Area Networks, the Internet, and mobile computing) that have the ability to transform relations with citizens, businesses, and other arms of government (Bahrain e-Government Authority, 2014). Huang and Bwoma (2003) identified e-Government as "An internet application that helps governments to deliver government services to the public, improve interactions with citizens, businesses and other government organizations, and facilitate access to government documents and information" (AlHujran, 2009). In the late of 1990s, governments became more aware of the benefits of exploiting internet and information technology to serve the society effectively. Initially, it has limited functions and only implemented in some governments for some reasons. Nowadays, the e-Government plays an important role in serving societies and businesses by providing to them different kinds of transactions and services at anytime and anywhere using a device that is capable to be connected to the internet.

The Bahraini Government was aware of the need to upgrade and improve the effectiveness and efficiency of government services through new electronic delivery channels. As one of the strategies to achieve Vision 2030, the government of Bahrain has introduced the e-Government Agency program that was previously launched by H.E. Shaikh Mohammed bin Mubarak al-Khalifa (the deputy Prime Minister) on 23/05/2007 (Bahrain e-Government Authority, 2011). Achieving next generation excellence in government is the vision of this project by delivering service efficiency with high quality, advocating proactive customer engagement, valuing efficiency, collaborating with all stakeholders, nurturing entrepreneurship, and encouraging innovation. The mission of this project is to comprehend the e-government vision in the country by managing and defining the implementation of relevant 
strategies, facilitating the transformation of services, setting and monitoring compliance with policies, and close collaboration with government entities, and finally effective collaboration with the private sector.

Many governments worldwide, including the Bahrain Government face the problem of low-level of citizen adoption of e-Government services. The success of e-Government depends heavily on the citizens' willingness to adopt this innovation. Unfortunately, Bahraini citizens still prefer to use traditional methods to make transactions, such as a phone call or in-person visit, than using the internet to interact with the government. According to the report by the Road Transport Department, people still spend time to line up at the counter to pay their summonses. A questionnaire was conducted by Bahrain e-Government Authority on the usage of e-Government services and the result was $7 \%$ of Bahraini citizens who used the e-Government services in 2008 and the usage of e-Government services were 40\% in 2009 (Bahrain e-Government Authority, 2009). In global perspective regarding to the usage of government website by citizens is only $30 \%$ (Kumar et al., 2007). Lack of citizens' adoption of e-Government services increases the government expenses, since huge investments from governments could be simply wasted.

Bahrain e-Government Authority believes that the success of e-Government relies heavily on citizens' awareness toward e-Government services; therefore, the e-Government Authority is conducting marketing and awareness campaigns through advertisements in print, audio and visual media and campaigns for sensitizing the public on the e-Government programs (Bahrain e-Government Authority, 2014). Therefore the main objective of this study is to empirically test the factors that influence citizens' adoption of e-Government among Bahraini citizens via trust, awareness, and culture through regression analysis.

\section{Literature Review}

\subsection{E-government Adoption}

Adoption of e-Government has become an important topic that many researchers were interested to study and conduct a research on, even though it was proven that it is one of the most challenging issues in information technology research. There are many different studies have been established toward adoption of e-Government by citizens and each has different results and findings. However, researchers have different findings and results, most of them agreed that the demand for e-Government services is very low, what forced them to search on the factors that influence on citizens' adoption of e-Government.

Usher et al. (2012) analysed the citizens' acceptance of e-government services via using the unified theory of acceptance and use of technology (UTAUT) which this theory has four predictors or determinants of usage intention that they are effort expectancy, performance expectancy, facilitating conditions, and social influence. Their findings are split into non-significant and significant factors in which non-significant factor is the social influence that did not have any effect on behavioural intention for e-government service usage. While the significant factors were, effort expectancy, performance expectations, facilitating conditions, and internet experience. Finally, they identified that age and gender have no direct effect towards citizen's behaviour to e-government service acceptance.

Alhujran, O. (2009) applied another theory for his study, which is Technology Acceptance Model (TAM). Alhujran findings were taken from two different resources, survey and case study. The survey was based on the internal and external variables of Technology Acceptance Model (TAM). The internal variables include perceived usefulness, perceived ease of use, attitude and intention to use the system. The external variables of TAM are national culture, trustworthiness and perceived public value. The case study findings are trust, trustworthiness, citizens' awareness of the available e-Government services, digital divide, culture, information security and privacy, service quality, perceived benefits and usefulness, ease of use, and ICT-literacy. The survey results of the research states that the internal variables, perceived usefulness and perceived ease of use have a significant positive impact on citizens' attitude toward using e-Government services. The most variable that has a major positive impact among the external variables of TAM is perceived public value. The overall finding of this study is that perceived public value has more influence on perceived ease of use than perceived usefulness (Jamali, Samadi, \& Marthandan, 2014).

A more careful study conducted by Akkaya et al. (2013) regarding to e-Government adoption by citizens in Germany, they found that the factors of data protection, privacy and security are the most factors that has a major influence on individuals' engagement to e-Government followed of the reliability of systems and completeness of information. The lowest factors that barely have influence e-Government adoption are information about status, convenience followed by a variety of services. From the research findings, they noticed that citizens' trust in government and technology, including the supporting infrastructure and the transmitting medium are very important to enhance citizens' intention to adopt the online services. 


\subsection{Culture}

Basically, there is no precise characterization of culture and due to the complications of defining this concept; Hofstede (1993) has suggested that culture is "The collective programming of the mind which distinguishes the members in one human group from another". Most of the times, researchers highlighted the prominence of culture and its connection to the realization of e-Government recognition and practical. Alshehri and Drew (2010) in their studies in regards to the challenges of e-Government acceptance in Saudi Arabia. Researchers found that the social barrier contribute as a great influence when it comes to citizens' intentions in adopting and accepting e-Government services. Furthermore, in their findings also indicates that cultural differences and digital divide are two main social issues that influence the acceptance of e-Government in Saudi Arabia. Besides that Alshehri and Drew (2010) also explained about other cultural issues which include social languages, education, features, backgrounds, religion, experiences and different anticipations towards e-government system. Based on the research done by Alshehri and Drew (2010) through surveys, clearly proofs that culture incompatibility is the main obstacle towards e-Government as indicated by finding more than $33 \%$ of respondents' outcome. Government clarifies that culture is difficult to resolute and is a complex issue, particularly when the provided e-Service involves the governments'-citizens' collaboration. In this case in order to resolve the cultural issue, citizens' culture and social attitude required to be addressed and studied in depth.

A qualitative study conducted by Al-Sowayegh (2012) on cultural drivers and barriers to the adoption of e-Government in the Kingdom of Saudi Arabia from the employees' perspective. The interview findings indicated that there are five cultural drivers that influence e-Government adoption, females working privately, extra financial support provided by females and their role in society, personal data search, exchange of ideas, knowledge and freedom online. Regarding to cultural barriers the author found from the interview findings that collectivism, grouping, nepotism, and loyalty, as well as, generation gap, attitudes towards outside influences and female constraints have a significant influence on the adoption of e-Government services. In addition, the author stated two cultural dimensions that have a direct effect on employees' adoption towards e-Government, which are cultural values and socio-structural practices. The cultural value dimension consists of two elements that are difficult to change as they are embedded and rooted in society. These elements are national background (history and beliefs) and national culture (cultural infrastructure). According to Al-Sowayegh (2012) "The socio-structural practices are elements in the culture that are always changing and are not as embedded in the cultural fabric as the cultural values". These elements include organizational, technological, political, educational, resources-based, and regulatory and legislative.

A deep study conducted by Nadi (2012) on the influence of culture on e-Government acceptance in Saudi Arabia. Based on the author's finding, there are several factors that have a significant positive influence on acceptance of e-Transactions. These factors are perspective on communication, conservation values, result demonstrability, compatibility, and trust in the Internet. Power and trust in government agencies have significant negative influence on acceptance of e-transactions. The finding also indicated the non-significant factors that have less influence on the acceptance of e-Transactions, which are relative advantage, complexity, social influence, and the following cultural values: achievement, hedonism, stimulation, self-direction, and benevolence.

Hofstede (1993) identified five dimensions of cultural variation. These dimensions are Power Distance (PD), Uncertainty Avoidance (UA), Individualism vs. Collectivism (IDV), Masculinity vs. Femininity (MAS) and Long-term vs. Short-term orientation (LTO). Employees in cultures scoring high PD, tend to complete tasks and duties assigned by supervisors even if they are unconfident of the supervisors merit or work ethic, because they believe that the power is unequally distributed (McCoy et al., 2007). But people from countries with low UA have more intention to take risks and to make individual decisions. In high collectivism and low individualism cultures, people prefer to be a part of groups and they respect other members' opinions. Cultures with high masculinity, men are socially pressured to excel but feminine cultures, both men and women supposed to be ambitious. In LTO cultures, people are considered as future oriented and more forward looking.

Another study conducted by Aldraehim et al. (2012) highlighted the cultural impact of e-Services use in Saudi Arabia. The study focused on nepotism since it has a major impact on Saudi society. The authors identified nepotism as "the employment of relatives, whether in the same organization or even working or being supervised by their relatives in the same department". The authors stated several causes for nepotism, which are sociocultural, economic, educational and political structures. The survey result indicated that nepotism has a negative predictor of intention to use e-Services. There is a weak negative relationship between nepotism and intention to use. 


\subsection{Awareness}

Awareness of e-Government refers to scope of knowledge and recognition, human has over e-Government services. A wide range of studies was conducted regardinging the factors and issues that affect citizens' awareness on e-Government services and many other studies recommended several strategies to increase citizens' awareness toward e-Government services. Choudrie and Dwivedi (2005) studied the citizens' awareness on e-Government initiatives in the UK. They found that there are several factors that have a significant influence on e-Government awareness, which are age, gender, education, social class, income and broadband access. The study indicated that as increases in the citizens' age ranges occurred, there was more awareness of and adoption of the Government gateway. Also, the study revealed that males are more aware of e-Government services than female. The majority of citizens who are aware of e-Government services are educated no matter the degree level is. Citizens who belong to social class 'E' are more aware of online services. The authors suggested that the awareness and adoption of e-government services decreases as the social class of respondents reduces. In addition, the study illustrates that almost all income segments are aware of the government gateway. They also found that citizens with home broadband access are more likely to adopt e-Government services.

Another study conducted by AlShishi (2006) highlighted strategies to increase citizens' awareness toward e-Government services. He argued that marketing and education are the most important strategies to enhance citizens' awareness. He suggested that governments should promote continuously on e-Government initiatives, in order to inform users about where and how to utilize them. Also, he suggested that providing ICT education and training courses to citizens and employees help to increase the level of their awareness on e-Services. He concentrated on awareness campaigns because they are very important to spread the e-Government concept to people who are not internet users and to make a positive first impression about the provided e-Services.

According to Alshehri and Drew (2010) survey results it was discovered that one of the barriers towards the awareness of e-Government services in Saudi Arabia are due to lack of programs in promoting the e-government services benefits and advantages. Various strategies have been enlisted by researcher to increase the citizens' awareness through Cross-media advertisements that consist of newspapers, brochures, TV, messages on public transport and subways, banners in public places, road shows and seminars that would also escalation e-government user population. Indicators show that initiatives by the Ministry of Information and Communication Technology (MICT) and the Yesser program can encourage the understanding and practice of e-government services in Saudi services among society.

\subsection{Trust}

Ooh Kim Lean (2008) states that trust develops in users when they believe the website is legal, ethical and trustworthy and is able to safeguard their confidentiality. The trust can also be defined as quantified reliance by a trust or respect towards the ability, trustworthiness, security and reliability of a trustee within a specified context (Hazeem, 2010; Nogoev et al., 2011). It is about the main factors that have emotional impact on citizens' inclination to use the e-Government service and considered the main obstacles to e-Government acceptance in Bahrain. Most of e-Government authorities is facing a major problem in the issue of lack of citizen's trust toward e-Government, which in turn motivated a wide array of researchers to focus their study bearing on the factors that can build citizens' trust. More often than seldom all of the studies carried out indicate that trust is the main factor that contributes t citizen's trust on e-Government success.

Thompsom et al. (2009) amongst other researcher also emphasized the significance of Trust on Government (TOG) and Trust on Internet (TOI) in the success of adopting e-Government into the government system. The citizen's trust on the government entity portrayed also affects the success of e-government Web site. Indirectly it can be said that trust in an e-government Web site is clearly associated with Trust in government. The successful formation of trust in government Web site is related to government-citizen relationship. Therefore, citizen's trust in government should directly motivate his or her trust in government Web sites. Web site user's trust towards the capability and security of the Internet can be taken as an indicator of the extend of individual trust in technology.

Lopez (2009) argued that to convey a trustworthy image, e-Government websites should be professionally designed with an appealing appearance, be reliable, and have high availability and security. Government leaders should implement the use of security mechanisms to the citizen through e-Government website. To increase trust government leaders should make public the personal data handling regulations and policies that are in effect in their agencies and implement audit process that ensure the implementation of those regulations and policies and the transparent management of e-Government transactions.

Several interviews were conducted by Omar Alhujran (2009) regarding to factors that build e-Government trust. 
He received a variety of responses from different interviewees. Interviewees indicated that increasing citizens' trust I requires by the government to make its e-services, trustworthy by implementing information security and privacy policies, on the government websites, providing reliable e-services, drafting and implementing related laws and regulations, transparency, and ensuring that citizens' queries will be adequate and quickly answered. In the same area of trust, Tee et al. (2014) and Zahir and Gharleghi (2015) show that security and trust are the main determinants of electronic ticketing in airline industries and well as internet banking adoptions.

\section{Methodology}

For the purpose of sample selection, this study has engaged a convenience sampling design to select the respondents. Purposive or non-probability sampling is also synonymous to convenience sampling. Khotari, 2004 has applied this method whereby this sampling method includes purposive or deliberate collection of specific units of the universe for establishing a sample which signifies the universe. He also explains that when population components are selected in the sampling without bias, it can be called convenience sampling. Employees from Bahrain have been taken as targeted population or the sampling frame for purpose of this research. Whilst, employees in the private sector are selected as a potential respondent. Only 140 responses were considered for this study from the total of 160 respondents selected due to some biased or unclear responses. The data were collected from March to May 2014.

After the data were collected from respondents, it was analyzed and organized by Statistical Package for the Social Sciences (SPSS). This software is used to run the regression and provide the analysis and the degrees of significance among the variables, namely, culture, awareness and trust with e-Government adoption.

\section{Empirical Findings}

This part presents the empirical findings of the study. Table 1 presents the demographic of the respondents.

Table 1. Demographic of all respondents

\begin{tabular}{llll}
\hline Variables & Options & Frequency & Percent \\
\hline Gender & Male & 65 & $45 \%$ \\
Age & Female & 78 & $55 \%$ \\
& $17-20$ years & 14 & $10 \%$ \\
& $20-25$ years & 63 & $44 \%$ \\
& $26-45$ years & 43 & $30 \%$ \\
Education & $46-55$ years & 21 & $15 \%$ \\
& 55 and above & 2 & $1 \%$ \\
& High school & 15 & $10 \%$ \\
Computer experience & College degree & 45 & $31 \%$ \\
& Bachelor degree & 60 & $42 \%$ \\
e-Commerce experience & Postgraduate degree & 23 & $16 \%$ \\
& Under 3 years & 19 & $13 \%$ \\
& 3-5 years & 47 & $33 \%$ \\
& More than 5 years & 76 & $54 \%$ \\
& Never & 45 & $32 \%$ \\
& About once a year & 12 & $9 \%$ \\
& A few times a year & 31 & $22 \%$ \\
& About once a month & 35 & $25 \%$ \\
\hline
\end{tabular}

From the frequency table it can be seen that, most respondents are femalewho are 20-25 years old and holding college degree with more than 5 years' work experience and had an e-commerce experience at least once a month.

\subsection{The Mean Results}

The table 2 below shows the mean and the standard deviation for each variable. Starting from the highest to the lowest mean results, the mean result of the level of awareness toward adoption of e-Government is 18.2443, while 
the standard deviation is 4.90383 . The mean for the level of Bahraini citizens' trust toward e-Government is 17.9220 and the standard deviation is 4.80932 and the mean for culture is 14.1119 and the standard deviation is 3.34857 .

Table 2. The mean results

\begin{tabular}{lll}
\hline Independent Variables & Mean & Standard Deviation \\
\hline Culture & 14.1119 & 3.34857 \\
Awareness & 18.2443 & 4.90383 \\
Trust & 17.9220 & 4.80932 \\
\hline
\end{tabular}

\subsection{Reliability}

The reliability test is a consistent measurement to examine the reliability when we have same respondents by providing the standard level of accuracy for variables. The popular test for reliability is "Cronbach alpha" test, and the standard rate for this test is 0.70 , i.e. if the value of reliability test is 0.70 or above, the variables is reliable. Empirical finding on this test are presented in Table 3.

Table 3. Cornbach alpha test

\begin{tabular}{ll}
\hline Variables & Value \\
\hline Culture & 0.831 \\
Awareness & 0.811 \\
Trust & 0.761 \\
e-Government Adoption & 0.842 \\
All variables & 0.881 \\
\hline
\end{tabular}

According to the table 3, all variables and data are reliable since the value of Cronbach alpha exceeds 0.70 .

\subsection{Multiple Regression Analysis}

Before we proceed to the regression analysis, we applied the ANOVA analysis which is used to determine whether there is any significant difference between the means of independent variables. According to the table 4, it is evident that there is no significant difference between the mean of considering variables, since the P-value is 0.000 and it is less than 0.05 .

Table 4. One-way ANOVA analysis

\begin{tabular}{llllll}
\hline ANOVA & Sum of Squares & df & Mean Square & F & Sig. \\
\hline Regression & 12.93 & 3 & 4.31 & 13.48 & 0.000 \\
Residuals & 11.87 & 83 & 0.14 & - & - \\
Total & 24.80 & 86 & - & - & - \\
\hline
\end{tabular}

In the second part the coefficient result of multiple regressions represented. Dependent variable in this table is e-Government adoption.

Table 5. Coefficients

\begin{tabular}{lllll}
\hline \multirow{2}{*}{ Variables } & \multicolumn{2}{l}{ Estimated coefficients } & t-stat. & \multirow{2}{*}{ Sig. } \\
& Beta & Std. error & 6.468 & 0.000 \\
\hline Constant & 1.127 & 0.174 & 3.151 & 0.000 \\
Culture & 0.208 & 0.066 & 2.594 & 0.001 \\
Awareness & 0.262 & 0.101 & 2.250 & 0.007 \\
Trust & 0.378 & 0.168 & \\
\hline
\end{tabular}


A total number of three variables were examined through regression analysis to determine the relationship between the three independent variables (culture, awareness and trust) and e-Government adoption. The relationship between the culture and e-Government adoption was found significant by 0.208 at the 0.01 level (2-tailed). The second variable i.e., awareness, was found significant by 0.262 at the 0.01 level (2-tailed). The third variable of trust also identified to be significant by 0.378 at the 0.01 level (2-tailed).

\subsection{Culture}

The findings of the regression analysis demonstrated that culture has a significant relationship with adoption of e-Government by 0.208 with significance level of 0.000 . This finding is being supported by many different researchers who found that culture has a significant relationship toward adoption of e-Government. A study conducted by Al-Shafi and Weerakkody (2009), they found that there is a positive relationship between social influence and behavioural intentions to use e-government services. Another study supports the results of this study was conducted by Nadi (2012). He found that cultural values which are power and conservation had a significant relationship toward e-Transactions. AlAteyah, Crowder, and Wills (2011) also found that the relationship between culture and e-Readiness of intention to adopt e-Government services is significant.

\subsection{Awareness}

Individuals' awareness toward e-Government services has a significant effect on the adoption of e-Government. The results of the conducted regression analysis indicate that there is a significant relationship between awareness and adoption of e-Government by $(0.208)$ with significance level of 0.001 . This study's findings are in the line with previous research conducted by AlShishi (2006) and Khojeh et al., (2013). AlShishi found that users' awareness about e-government in Oman correlates positively with willingness to use e-government with a coefficient correlation of (0.198). Another study supports the study results, was conducted by Mofleh, S and Wanous, M. (2008). There result of their regression analysis indicated that there is a significant relationship between awareness and intention to use e-Government has a significant with a coefficient correlation of 0.12 and the significance level of (0.002).

\subsection{Trust}

The findings of the regression test demonstrate that trust has a significant influence toward e-Government adoption by 0.378 with the significance level of (0.007). Many previous studies highlighted the importance of trust toward e-Government adoption. Mofleh and Wanous (2008) conducted a multiple linear regression analysis to determine the relationship between intention to use e-Government and trust. The analysis result states that trust on the internet and trust in the government had a significant influence in predicting citizen intention to use e-Government services with a coefficient of 0.177 and 0.326 and a significance level of 0.000 for both. Another study that supports the findings of this study was conducted by Carter and Belanger (2008). They discovered that trust of the internet and trust of the government positively affects intention to use e-Government. Figure 1 summarizes the regression findings:

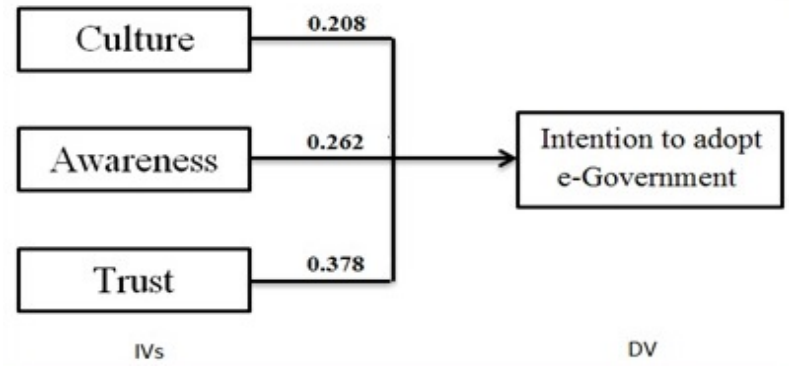

Figure 1. Summary of regression analysis

\section{Conclusion}

This paper examined the relationship among the culture, awareness, and trust towards e-Government adoption in Bahrain. This paper presented the mean and the standard deviation of the variables as well as the regression test results. The result of the regression analysis supports the effect of trust, awareness, and culture towards e-Government adoption in Bahrain since all the three variables found to have a significant relationship with dependent variable. Among the independent variables, trust shows the highest impact on the e-Government adoption. 


\section{References}

Akkaya, C., Wolf, P., \& Krcmar, H. (2013). A Comprehensive Analysis of E-Government Adoption in the German Household. $11^{\text {th }}$ International Conference on Wirtschaftsinformatik, $27^{\text {th }}$ Feb- $1^{\text {st }}$ Mar, Leipzig, Germany

Alateyah, S., Crowder, R., \& Wills, G. (2011). Factors Affecting the Citizen's Intention to Adopt E-government in Saudi Arabia. International Journal of Management Science and Engineering, 7(9), 561-567.

Aldraehim, M., Edwards, S., Watson, J., \& Chan, T. (2012). Cultural Impact on e-Service Use in Saudi Arabia: The Role of Nepotism. International Journal for Infonomics, 5(3/4), 655-662.

Alhujran, O. (2009). Determinants of e-government services adoption in developing countries: A field survey and a case study. $\mathrm{PhD}$ Thesis, University of Wollongong.

Al-Shafi, S., \& Weerakkody, V. (2009). Understanding Citizens Behavioural Intention in the Adoption of E-government Services in the State of Qatar. Proceedings of the $17^{\text {th }}$ European Conference on Information Systems (ECIS2009). Verona, Italy.

Alshehri, M., \& Drew, S. (2010). Challenges of e-Government Services Adoption in Saudi Arabia from an e-Ready Citizen Perspective. World Academy of Science, Engineering and Technology, 4, 891-897.

Alshehri, M., Drew, S., Alhussain, T., \& Alghamdi, R. (2012). The Effects of Website Quality on Adoption of E-Government Service: An Empirical Study Applying UTAUT Model Using SEM. $23^{\text {rd }}$ Australasian Conference On Information Systems, 3-5 Dec, Geelong.

AlShishi, H. (2006). Critical Factors in the Adoption and Diffusion of E-Government Initiatives in Oman. $\mathrm{PhD}$ thesis, Victoria University, Australia.

AL-Sowayegh, G. A. (2012). Cultural Drivers and Barriers to the Adoption of E-government in the Kingdom of Saudi Arabia. A Thesis submitted to the University of Manchester.

Carter, L., \& Belanger, F. (2004). The Influence of Perceived Characteristics of Innovating on e-Government Adoption. Electronic Journal of E-government, 2(1), 11-20.

Choudrie, J., \& Dwivedi, Y. (2005). Citizens Awareness and Adoption of e-Government Initiatives in the UK. e-Government Workshop '05 (eGOV05). Brunel University, West London, UK.

Hazeem, H. (2010). Bahrain e-Government Program: Workshop on Building Trust and Confidence in Arabic e-Services. Retrieved from http://css.escwa.org.lb/ictd/1246/pt34.pdf

Hofstede, G. (1993). Cultural Constraints in Management Theories. Academy of Management Executive, 7(1), 81-94.

Huang, Z., \& Bwoma, P. O. (2003). An Overview of Critical Issues of e-government'. Issues of Information Systems, 4(1), 164-170.

Jamali, K., Samadi, B., \& Marthandan, G. (2014). Prioritizing Electronic Commerce Technologies in Iranian Family SMEs. Interdisciplinary Journal of Contemporary Research in Business, 6(2), 148-180.

Khojeh, E., Mohseni, S., \& Samadi, B. (2013). Enhancing Customer Satisfaction Among SMEs through Web Technology. Research Notes in Information Science, 11, 13-28.

Kothari, C. (2004). Research methodology (1st ed.). New Delhi: New Age International (P) Ltd.

Kumar, V., Mukerji, B., Butt, I., \& Persaud, A. (2007). Factors for Successful e-Government Adoption: A Conceptual Framework. The electronic journal of e-Government, 5(1), 63-76.

Lopez, C. (2009). Barriers to Electronic Government Use as Perceived by Citizens at the Municipal Level in Mexico. Google Books

McCoy, S., Galletta, D., \& King, W. (2007). Applying TAM across Cultures: The Need for Caution. European Journal of Information Systems, 16(1), 81-90. http://dx.doi.org/10.1057/palgrave.ejis.3000659

Mofleh, S., \& Wanous, M. (2008). Understanding Factors Influencing Citizens Adoption of e-Government Services in the Developing World: Jordan as A Case Study. Journal of computer Science, 7(2), 1-11.

Nadi, I. (2012). Influence of Culture on e-Government Acceptance in Saudi Arabia. PhD thesis, arXiv preprint arXiv:1307.7141.

Nogoev, A., Yazdanifard, R., Mohseni, S., Samadi, B., \& Menon, M. (2011). The Evolution and Development of E-Commerce Market and E-Cash. In International Conference on Measurement and Control Engineering 2nd (ICMCE 2011). ASME Press. http://dx.doi.org/10.1115/1.859858.paper35 
Ooh, L. K. (2009). Factors Influencing Intention to Use e-Government Services among Citizens in Malaysia. International Journal of Information Management, 29(6), 458-475. http://dx.doi.org/10.1016/j.ijinfomgt. 2009. 03.012

Tee, P. K., Gharleghi, B., Chan, Y. F. B., \& Lim, M. K. (2014). Electronic Ticketing in Airline Industries among Malaysians; the Determinants. International Journal of Business and Social Science, 5(9), 168-174.

Teo, S. H. T., Shirish, C. S., \& Jiang, L. (2009). Trust and Electronic Government Success: An Empirical Study. Journal of Management Information Systems, 25(3), 99-131. http://dx.doi.org/10.2753/MIS0742-122 2250303

Zahir, M., \& Gharleghi, B. (2015). Adoption of Internet Banking in Maldives, the Most Important Determinants. Asian Social Science, 11(2), 181-189. http://dx.doi.org/10.5539/ass.v11n2p181

\section{Copyrights}

Copyright for this article is retained by the author(s), with first publication rights granted to the journal.

This is an open-access article distributed under the terms and conditions of the Creative Commons Attribution license (http://creativecommons.org/licenses/by/3.0/). 